\title{
A COMPARATIVE STUDY OF CONTACT STRESS FROM DIFFERENT STANDARDS FOR SOME THEORETICAL STRAIGHT BEVEL GEAR
} PAIRS

\author{
Edward E. Osakue ${ }^{1}$, Lucky Anetor ${ }^{2}$ \\ ${ }^{1}$ Department of Industrial Technology, Texas Southern University, Houston, Texas, USA \\ ${ }^{2}$ Department of Mechanical Engineering, Nigerian Defence Academy, Kaduna, Nigeria
}

\begin{abstract}
ANSI/AGMA 2003-B97, ISO 10300 standards and a new contact stress model are used to estimate and compare contact stresses in some theoretical straight bevel gear pairs. The contact stress expressions in the different gear standards and new model are formatted to highlight the similarity and differences. The power range of 10 to $15,000 \mathrm{~kW}$, backend modules of 2.5 to $25 \mathrm{~mm}$ and backend pitch velocities of 4.58 to $25.37 \mathrm{~m} / \mathrm{s}$ are covered. The results indicate that the percentage differences between the new contact stress and AGMA models are in the range of $2.22 \%$ to $7.40 \%$. These differences are small but can mean significant improvement in the pitting life expectancy of the gears since life and contact stress is related by a power law of approximately 9th degree. For example, a 5\% decrease in contact stress could mean a pitting life increase of about 50\%. The percentage differences between the new and ISO 10300 models contact stresses are in the range of $-6.57 \%$ to $67.34 \%$. These are large differences, indicating that much shorter pitting life should be expected based on the ISO model. The differences from The ISO 10300 standards may be attributed to the use of the mid facewidth cone radius in its contact stress model while the new model and AGMA standards use the backend cone radius which is larger than the mid facewidth cone radius. Another contributing factor to the differences is that the load service factor values evaluated from ISO methods are generally higher than those of the new model values which are based largely on AGMA methods. Since the ANSI/AGMA standards yield results that are considered to be conservative and the new contact stress model gives values that are marginally lower than the AGMA predictions, the new contact stress model deserves some serious considerations.
\end{abstract}

$* * *$

\section{INTRODUCTION}

Straight bevel gears have teeth cut on the frustum of a cone, therefore a gear pair must have a common apex for them to roll without sliding. This ensures that the pitch surfaces of two meshing straight bevel gears are proportional to the distance from the common apex. Because the pitch surfaces of bevel gears are conical, the tooth profile at the front end or toe is smaller in size and shape than that at the backend or heel, the larger end of bevel gears. The maximum gear ratio for bevel gear speed reducers is 10 and 5 for speed increasers [1]. Bevel gears are normally made as matched sets as they are generally not interchangeable. The teeth of most bevel gears are crowned in the axial and radial directions during manufacture [2]. Crowning modifies the surface profiles so that the teeth have convex surfaces along the face width. It allows gears to accommodate deflections and tooth variations and prevent concentration of contact stress at the edges of the gear teeth. Most bevel gears are made from case-carburized steels [1].

Contact stress standards for straight bevel gears are based on similar concepts of Hertz contact stress, equivalent spur gear and rated load modification. The German physicist, Henry Hertz developed expressions for the stresses created when curved frictionless surfaces are loaded in normal contact in 1881. The Hertz contact stress model was first applied in gearing technology by Buckingham [3]. He developed an equation for gear pitting resistance which has been adopted and modified by national and international standard organizations such as American Gear Manufacturers Association (AGMA) and International Standardization Organization (ISO) in gear design technology. Other commonly used standards are Deutsches Institut fur Normung (DIN), and Japanese Industrial Standards (JIS) but the most popular standards are the ISO and AGMA standards [4]. ANSI/AGMA 2003-B97 [5], is a popular bevel gear design standard in the United States and provides a conservative means of estimating the contact and bending stresses in straight, zero, and spiral bevel gears [2]. ISO 10300 standards [6] provide guidance on the estimation of the contact and bending stress capacities of bevel gears $[6$, 7].

Perhaps due to the geometric complexities of bevel gears, the concept of equivalent spur gears was developed. Simply, an equivalent spur gear of a bevel gear is one that is proportioned such that it has the same load capacity as the bevel gear. Bevel gear teeth are cut on conical surfaces and have a spherical geometry, so the involute tooth profile should be developed on a spherical surface to ensure conjugate action. Since the projection of bevel gear teeth on the surface of a sphere would indeed be a difficult and time- 
consuming problem, it is necessary practically, to approximate bevel gear tooth profile as accurately as possible. The "Tredgold's approximation" is commonly accepted and it uses the cone tangent to the sphere at the pitch point on the backend of the bevel gear to define the pitch radius of an equivalent spur gear. The basic shape of a bevel gear tooth is almost the same as that of this spur gear $[8,9,10]$. The Tredgold's approximation is almost universally used and as long as the bevel gear has 8 or more teeth, it is accurate enough for practical purposes [11]. Therefore, the manufacturing dimensions of a bevel gear are based on the bevel gear backend module which is largely standardized.

It is known in practice that actual load on gears are higher than the rated or nominal values. The increase in load is attributed to tolerances on gear and housing sizes, manufacturing imperfections, errors in assembling and installation, unbalanced rotating and or reciprocating masses, internal vibrations, etc. [12, 13]. In order to address this situation, AGMA and ISO gear design approaches apply a series of modification factors to approximate actual load and actual strengths in gear design [14, 15]. Differences in the approaches manifest in the number of applied modification factors and their evaluation methods. Consequently, numerical results from these standards can differ considerably [16].

In theory, any gear standard may produce a satisfactory design of a gearset, however, globalization of the economy and technology now demands that successful designs in the market place must be competitive in price. Specialized gear designs must of necessity be conducted in compliance with relevant standards and when customers prefer a particular standard or code, the client's desire must be honored. A working knowledge of more than one gear standard is desirable today, especially if the product is aimed at international market [15]. Therefore, it is important to understand the similarities and differences between the standards of interests in design applications.

According to Bergseth [17], AGMA and ISO standards for surface durability calculations are generally time consuming and can be difficult. ISO 6336 standards require much more design detail than AGMA standards, which tend to have fewer modification factors and thus simpler. When the ratings of identical cylindrical gearsets by AGMA 6011 (1998) and ISO 6336 (1996) are compared, substantial differences are found. The durability rating for thruhardened steel gears is approximately the same from the two standards, but the durability rating of carburized steel gears by ISO 6336 standard is higher than that of AGMA standard. The bending strength rating by ISO 6336 standard is generally higher than that of AGMA standards [18]. A study by KISSsoft [16] shows that safety factors calculated for some bevel gearsets differ considerably depending on the rating standard (AGMA 2003 or ISO 10300) used. Also, their results show that contact stresses for small straight bevel gears were higher for ISO standard than AGMA estimates but lower for larger gears. The differences were attributed to values of design factors such as load distribution, size, and crowning. Consequently, "AGMA 2003 and ISO 10300 yield results that cannot be compared" [16]. From the above, rating standards of AGMA and ISO can yield different results for the same design situation and it can be confusing when the results are compared. Therefore, it is important for now that a gear designer understands at least one standard and consistently use it while being familiar with some other standards.

In a study by Osakue and Anetor [19], comparison of contact stresses from ASNI/AGMA 2003-B97 standards and a new straight bevel gear contact stress model for low power $(<10 \mathrm{~kW})$ was made. It was found that the new contact stress model results were marginally lower than the AGMA values. In a similar but different study, contact stress estimates from ISO 10300 and the new contact stress model were compared [20]. It was found that the new contact stress model results were significantly lower than the ISO values. The experience from the aforementioned studies naturally leads to inquiring what the results might be for medium and higher kilowatts bevel gear drives. In this study, contact stresses based on AGMA 2003-B97 [5], ISO 10300 [6] and the new contact stress model for some theoretical straight bevel gear pairs in the power range of 10 to $15,000 \mathrm{~kW}$ are estimated and compared. The contact stress expressions for the standards and new model are formatted to bring out similarity and differences. The new contact stress model uses ANSI/AGMA methods for evaluating load influence modification factors because they are simpler.

\section{BEVEL GEAR LOADS}

In the design analysis of bevel gears, the load is commonly assumed to be applied at the mid-face width. The resultant forces actually act somewhere between the midpoint and the backend of the tooth width [10]. This means the force components used in design analysis are slightly over-rated. It should be noted that the complexities of the tooth profile of bevel gears make precise analysis rather very complicated and such a conservative approach is justified.

Fig. 1a depicts a bevel gear under load with the three components of the contact force shown at the mid-plane pitch point. Fig. 1b shows the transverse plane at the midplane pitch point which is obtained by looking in the direction of the shaft axis. The pitch diameter of the bevel gear at this point is indicated. This plane may be called the transverse kinetic plane since the operating tangential and radial force components on the physical bevel gear are defined on this plane. The axial kinetic plane is not shown but contains the tangential and axial force components. The tangential force is the driving force, the radial and axial forces are generated due to the gear pressure angle and the cone pitch angle for bevel gears. 


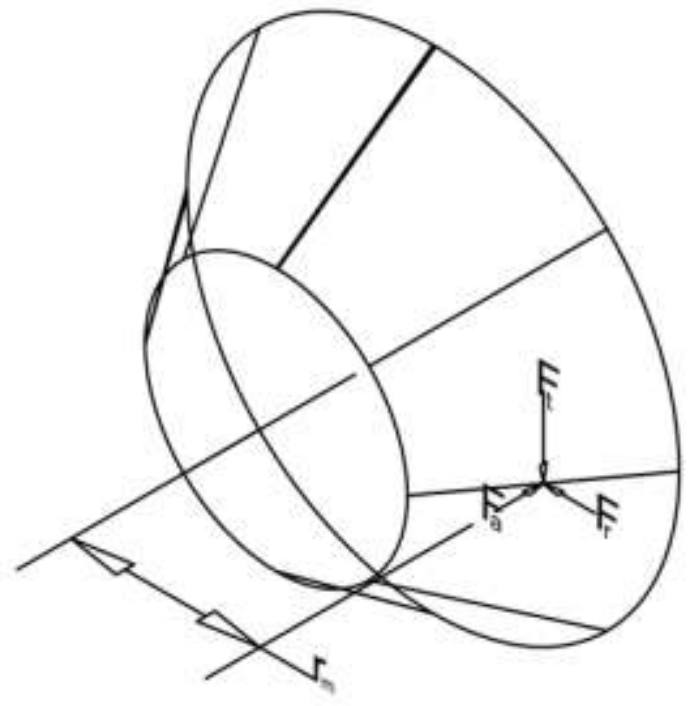

a) $3 \mathrm{D}$ force representation

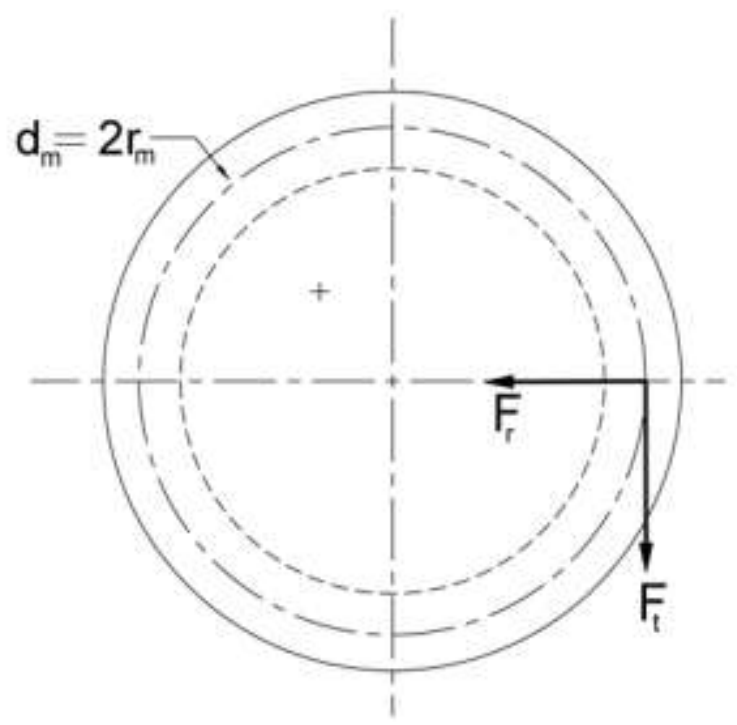

b) Transverse plane forces

Fig 1: Bevel gear force components

Referring to Fig. 1:

$F_{t}$ - transmitted or tangential force $(\mathrm{N})$

$F_{r}-$ radial force $(\mathrm{N})$

$F_{a}-$ axial force $(\mathrm{N})$

$r_{m}-$ mid facewidth pitch radius $(\mathrm{mm})$

The torque load on the pinion is:

$$
T_{1}=\frac{30 P_{1} \times 10^{3}}{\pi N_{1}}
$$

The actual gear ratio for a gearset is:

$$
\mu=\frac{T_{2}}{T_{1}}=\frac{N_{1}}{N_{2}}=\frac{z_{2}}{z_{1}}
$$

$P-$ transmitted power $(\mathrm{kW})$

$T-$ transmitted torque $(\mathrm{Nm})$

$N$ - rotational speed (rpm)

$z$ - number of teeth

$\mu$-actual gear ratio

1 - Subscript for pinion

2 - Subscript for gear

Please note that there are three (3) terms or sub equations in Eq. (2): equations (2a), (2b), and (2c) from left to right. All other equations with multiple terms should be interpreted, similarly.
The transmitted force is:

$$
F_{t}=\frac{2 T_{1} \times 10^{3}}{r_{m 1}}=\frac{2 T_{2} \times 10^{3}}{r_{m 2}}
$$

In bevel gears, the radial distance to a point on the cone from the shaft axis in the transverse plane is a linear function of the distance of that point from the apex of the cone. Therefore:

$$
F_{t}=\frac{2 K_{b} T_{1} \times 10^{3}}{d_{e 1}}=\frac{2 K_{b} T_{2} \times 10^{3}}{d_{e 2}}
$$

$$
\begin{aligned}
& K_{b} \text { - bevel load factor } \\
& d_{e} \text { - backend pitch diameter }(\mathrm{mm})
\end{aligned}
$$

From Fig. 2a and by similar traingles:

$$
K_{b}=\frac{L_{e}}{L_{m}}=\frac{m_{e}}{m}=\frac{L_{e}}{L_{e}-0.5 b}
$$

$L_{m}-$ mid facewidth cone distance $(\mathrm{mm})$

$L_{e}$ - backend cone distance (mm)

$m$ - mid facewidth module ( $\mathrm{mm}$ )

$m_{e}$ - backend module $(\mathrm{mm})$ 
The other forces are:

$$
F_{n}=\frac{F_{t}}{\cos \phi}
$$

$$
F_{r}=F_{t} \tan \phi \cos \varphi \quad F_{a}=F_{t} \tan \phi \sin \varphi
$$

\section{SPUR GEAR GEOMETRIC EQUIVALENCE}

Fig. 2a shows the axial plane of a straight bevel gear while Fig. $2 \mathrm{~b}$ shows the transverse plane at the backend. The basic physical gear size parameters are shown in these figures, except the module. Figs. $3 \mathrm{a}$ and $3 \mathrm{~b}$ show the geometrically equivalent or virtual spur of a bevel gear. The tooth profile of a spur gear lies in the transverse plane. Similarly, the tooth profile of the virtual spur gear for a bevel gear lies in the transverse plane. It should be noted that the virtual spur gear pitch circle radius maps onto the backend cone radius of the physical bevel gear, not the tooth mid-width cone radius where operating forces are evaluated. Conceptually, it is important to separate the physical bevel gear from the virtual spur gear to avoid confusion in the kinetic relationship between the two objects.

In Figs. 2 and 3:

$r_{e}-$ general backend pitch radius (mm)

$d_{e}$ - general backend pitch diameter ( $\mathrm{mm}$ )

$d_{o}$ - general backend outside diameter ( $\mathrm{mm}$ )

$d_{r}$ - general backend root diameter $(\mathrm{mm})$

$b$ - general facewidth (mm)

$\varphi$ - general pitch angle (deg.)

$r_{t}-$ virtual spur gear general pitch radius $(\mathrm{mm})$

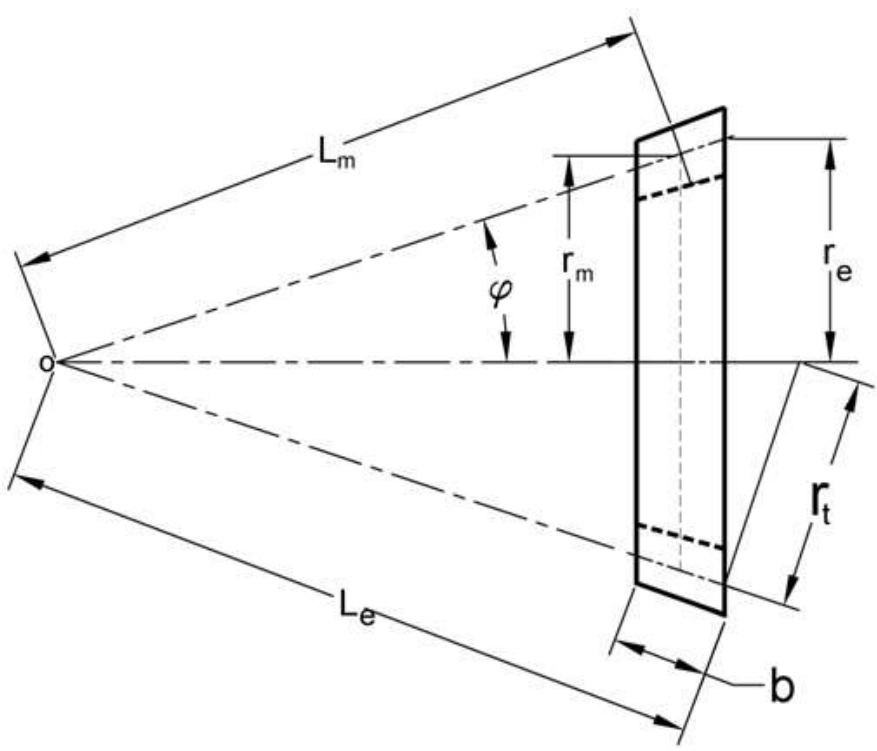

a) Axial plane

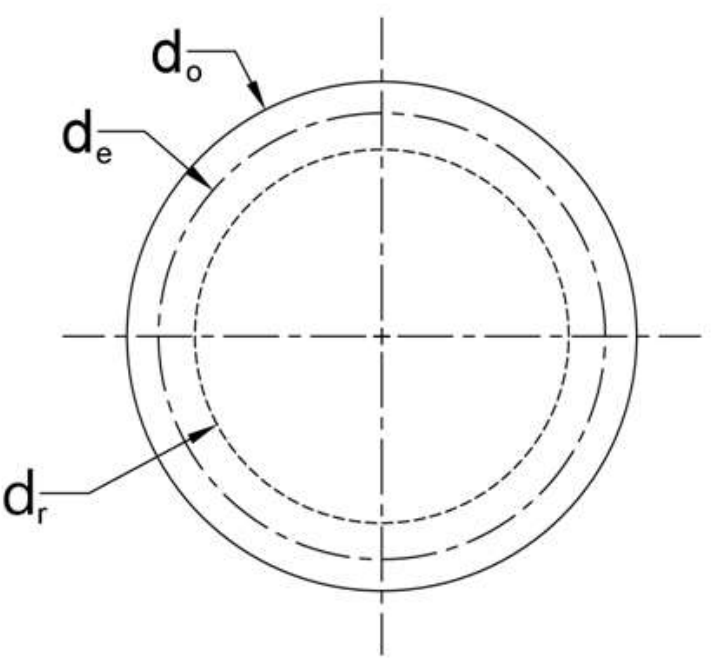

b) Transverse plane

Fig 2: Physical bevel Gear 

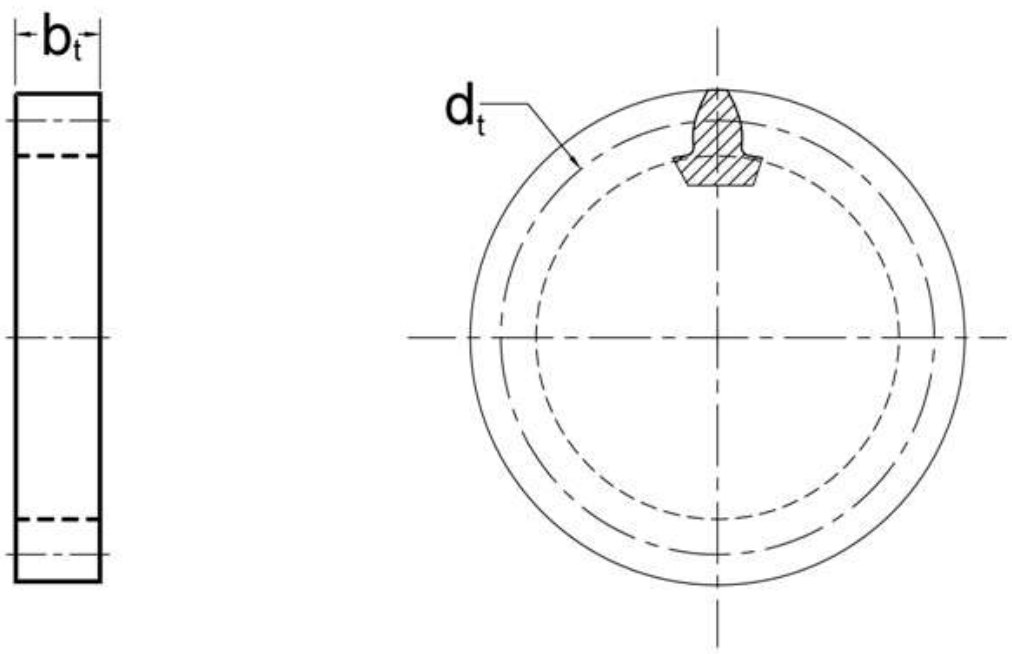

a) Axial plane

b) Transverse plane

Fig 3: Virtual spur Gear

The basic parameters of the virtual spur gears are:

$$
\begin{gathered}
r_{t}=\frac{r_{e}}{\cos \varphi}, \\
d_{t}=\frac{2 r_{e}}{\cos \varphi}=\frac{d_{e}}{\cos \varphi} \\
b_{t}=b
\end{gathered}
$$

$d_{t}$ - virtual spur gear general pitch diameter $(\mathrm{mm})$

$b_{t}-$ virtual spur gear general facewidth $(\mathrm{mm})$

\section{GEAR TOOTH FORM AND MODIFICATIONS}

A gear tooth form in the involute gear system is characterized by the pressure angle and Osakue and Anetor [12] defined a geometric parameter, called contact stress tooth form factor, that accounts for standard gear pressure angle and pi $(\pi)$ which relates to the contact patch area. This parameter is expressed as:

$$
K_{f}=\frac{2}{\pi \sin 2 \phi_{t}}
$$

$K_{f}$ - contact stress tooth form factor

$\phi_{t}$ - transverse pressure angle

\subsection{Tooth Profile Modified Gear}

The trend in the gear industry is the increasing use of tooth profile modified gears in power transmission for better performance and other areas and attempts to standardize correction factors is in progress [10]. This appears to be a viable economic approach to increasing the power density of gearboxes and reducing noise at higher operating speeds. Though several techniques are available, addendum modification and crowning are the more popular currently. Addendum modification is a treatment performed on gear teeth that can lengthen or shorten the proportion of the addendum portion of the gear tooth during manufacturing. Addendum modified gears can have a working pressure angle different from that of the standard profile. The working pressure angle is obtained as [10]:

$$
\operatorname{inv} \phi_{w t}=\operatorname{inv} \phi_{t}+\frac{2 \mathrm{~s}_{\mathrm{x}} \tan \phi_{t}}{z_{1}+z_{2}}
$$

$\phi_{w t}$ - working transverse pressure angle

$\mathrm{s}_{\mathrm{x}}-$ residual profile modification factor

where:

$$
\operatorname{inv} \phi=\tan \phi-\phi(\mathrm{rad})
$$

$\phi$-general pressure angle

And

$$
\mathrm{s}_{\mathrm{x}}=\mathrm{x}_{1}+\mathrm{x}_{2}
$$

$\mathrm{X}$ - tooth profile modification factor

Explicitly modifying pitting resistance capacity expressions for tooth profile correction is needful. It may be defined as: 


$$
K_{p}=\frac{\tan \phi_{t}}{\tan \phi_{w t}}
$$

$K_{p}$ - contact stress profile modification factor

$K_{p}$ can be deduced from the zone factor model of ISO (please see Eqs. (B2) and (B7) in Appendix B). The parameter appears $K_{p}$ as a numerator in contact stress capacity models as may be verified in Eqs. (15), (23), and (28). Note that $s_{x}$ may be zero or different from zero. When $s_{x}$ is zero, the transverse pressure angle of the gearset is unaffected by profile modification. If $s_{x}$ is non-zero and positive in value, the transverse pressure angle is increased and the contact stress reduced because $K_{p}$ is below unity. If $\mathrm{s}_{\mathrm{x}}$ is non-zero and negative in value, the transverse is decreased and $K_{p}$ is above unity, resulting in increased contact stress. For standard profile gears or when $s_{x}$ is zero, $K_{p}$ is unity.

\subsection{Crowned Gear Teeth}

The tooth flanks of standard or uncrowned bevel gears are flat in the axial direction but can be modified by profile and or lead crowning $[2,3,21]$. In profile crowning, the tooth flanks are modified into curved faces in the axial direction by barreling. Therefore, the thickness of the tooth at the center is more than at the ends and this prevents contact at the ends of the gear tooth during meshing. When crowning is done in the transverse plane, it is called lead crowning, but this often involves a reduction of root tooth thickness, weakening the gear in bending resistance. Sometimes both profile and lead crowing are combined. Crowning reduces the need to accurately align the axes of mating gears to be exactly parallel [3] and reduces gear noise. It decreases the sensitivity of gearsets to misalignment and errors in manufacturing and assembly, reducing the uneven stress distribution along the gear face width.

However, crowning produces localized contact [3] that makes the contact patch more elliptical than rectangular. This may lead to increased contact stress that can reduce gear durability. A variant of tooth crowning is tip relief which is an axial modification largely limited to the tip corners of the gear tooth. It is not as effective as crowing, but nonetheless prevents edge contacts at the ends of gear teeth [22]. ANSI/AGMA 2003-A86 [23] suggest a crowning factor of 1.0 for uncrowned teeth and 1.5 for crowned teeth for straight bevel gears contact stress estimates. ISO 10030 has an expression that can be used to estimate crowning effect in spiral bevel gears [7] which has been applied to straight bevel gears [19].
The combined influence of standard gear tooth profile, profile modification, and crowing may be captured by the parameter:

$$
K_{H}=K_{f} K_{p} K_{x}
$$

$$
\begin{aligned}
& K_{H}-\text { involute gear contact stress factor } \\
& K_{x}-\text { tooth crowing or ellipticity factor }
\end{aligned}
$$

The parameter $K_{H}$ quantifies the influence of standard gear profile and its modifications on the contact stress of plain cylinders in normal contact (the original Hertz formulation) when the plain cylinders have diameters equal to pitch diameters of the meshing gear pairs.

\subsection{Service Load Factor Estimate}

The service load factor was introduced as an aggregated design parameter to account for significant load influence factors in gear design [12]. It seeks to adjust the rated load to the value of the actual load expected in service. The service load factor is a magnification factor and takes care of load excitations beyond the rated value that are reoccurring in nature, not the peak load which occurs only occasionally. It is estimated using a multiplicative rule as shown in Eq. (16?) below.

$$
K_{s}=K_{a} K_{v} K_{m} K_{r} K_{c}
$$

$K_{s}$ - service load factor

$K_{a}$ - application or external overload factor

$K_{v}$ - internal overload or dynamic factor

$K_{m}$ - mounting or mesh overload factor

$K_{r}$ - rim flexibility load factor

$K_{c}-$ contact quality factor

The service load factor components evaluation methods are based on experience and experimental data. Thus, it represents attempts to match the predictions of theoretical gear design models with practical results. Consequently, it transforms theoretical gear design models into engineering models. Please refer to the Appendix A for more discussions on the component parameters in Eq. (16). The service load factor has been incorporated in the contact stress formulas given below for ease of computation and comparisons. Due to the number of factors and evaluation methods adopted by different gear standards, the numerical values predicted can be very different for the same design situation.

\subsection{Equivalent Gear Ratio}

Bevel gear meshes must be considered in pairs because the pitch cone angles are restricted by the gear ratio [24]. In conventional configuration of bevel gearsets, the shaft angle is: 


$$
\varphi_{0}=\varphi_{1}+\varphi_{2}
$$

$\varphi_{o}-$ shaft angle (deg.)

$\varphi-$ pitch angle of pinion (deg.)

With reference to [25] and when $\varphi_{o} \leq 90^{\circ}$, the cone pitch angles are obtained as:

$$
\begin{array}{r}
\tan \varphi_{1}=\frac{\sin \varphi_{o}}{\mu+\cos \varphi_{o}}, \\
\tan \varphi_{2}=\frac{\mu \sin \varphi_{o}}{1+\mu \cos \varphi_{o}}
\end{array}
$$

When $90^{\circ}<\varphi_{o}<180^{\circ}$ [26], it can be shown that:

$$
\begin{aligned}
& \tan \varphi_{1}=\frac{\sin \left(180^{\circ}-\varphi_{o}\right)}{\mu-\cos \left(180^{\circ}-\varphi_{o}\right)} \\
& \tan \varphi_{2}=\frac{\mu \sin \left(180^{\circ}-\varphi_{o}\right)}{1-\mu \cos \left(180^{\circ}-\varphi_{o}\right)}
\end{aligned}
$$

The virtual or equivalent gear ratio of a straight bevel gearset [19] is:

$$
\mu_{e}=\mu \frac{\cos \varphi_{1}}{\cos \varphi_{2}}
$$

$\mu_{e}-$ virtual gear ratio

Please note that equations (17) and (20) do not apply to crown bevel gears where $\varphi_{2}=90^{\circ}$.

\section{DIFFERENT CONTACT STRESS MODELS}

ANSI/AGMA 2003-B97 [5] standard provides contact and bending stress expressions for straight, zero, and spiral bevel gears. The contact stress expression for straight bevel gears is:

$$
\begin{aligned}
& \sigma_{H}=Z_{K} Z_{E} \sqrt{\frac{K_{s} K_{x} K_{b} F_{t}}{d_{e 1} b Z_{I}}} \\
& =Z_{K} Z_{E} \sqrt{\frac{2 K_{s} K_{b} K_{x} T_{1} \times 10^{3}}{d_{e 1}^{2} b Z_{I}}}
\end{aligned}
$$

Where:

$$
\begin{gathered}
Z_{E}=\sqrt{\frac{E_{c} \times 10^{3}}{2 \pi}} \\
E_{c}=\frac{2 E_{1} E_{2}}{E_{2}\left(1-v_{1}^{2}\right)+E_{1}\left(1-v_{2}^{2}\right)} \\
b=\min \left(b_{1}, b_{2}\right)
\end{gathered}
$$

$\sigma_{H}$ - maximum Hertz contact stress (MPa)

$Z_{K}$ - bevel gear factor

$Z_{E}-$ material elasticity coefficient (Pam0.5)

$Z_{I}$ - AGMA pitting geometric factor

$E_{c}$ - Composite elastic modulus (GPa)

$E$ - elastic modulus (GPa)

$v$ - Poison's ratio

$b_{1}, b_{2}-$ facewidth of pinion, gear $(\mathrm{mm})$

The $Z_{K}$ factor adjusts the contact stress so as to allow the rating of bevel, spur and helical gears with the same allowable contact stress numbers for any material [8]. It has a value of 0.634 for AGMA 2003-A86 bevel gear standards. The "ZI" in AGMA formula is adjusted for conically inclined and tapered teeth, load shearing, location of the most critical load and standard practice [8]. Other factors incorporated are the relative radius of curvature and gear inertia [1]. Analytical evaluation of this parameter is complicated [27], so AGMA provides charts and graphs based on results from numerical methods and experimentation. A problem with the use of charts and graphs is reading error, especially at low values of pinion teeth number. If care is not taken at such low pinion teeth numbers, considerable error may be introduced to the estimated contact stress values.

\subsection{ISO Models}

Bevel gear design standards are defined in ISO 10300 [6] which provide one expression for gears with uncrowned teeth and another expression for gears with crowned teeth. These two expressions are combined into one formula below. The contact stress model for straight bevel gears may then be expressed as (please refer to the Appendix B for proof):

$\sigma_{H}=1.05\left[\frac{2 K_{s} K_{H}\left(\mu_{e}+1\right) \cos \varphi_{2} E_{c} T_{1}}{\varpi_{t} d_{1} d_{2} b}\right]^{\frac{1}{2}} \times 10^{3}$

Where: 


$$
d=z m
$$

$d-$ mid facewidth pitch diameter ( $\mathrm{mm})$

The number of teeth on the virtual spur gearset for straight bevel gears is estimated as:

$$
z_{v 1}=\frac{z_{1}}{\cos \varphi_{1}} \quad z_{v 2}=\frac{z_{1}}{\cos \varphi_{2}}
$$

$z_{v}-$ virtual number of teeth

Define $k_{1}$ and $k_{2}$ :

$$
\begin{aligned}
& k_{1}=0.5\left[\sqrt{\left(z_{v 1}-2\right)^{2}-\left(z_{v 1} \cos \phi_{t}\right)^{2}}-z_{v 1} \sin \phi_{t}\right] \\
& k_{2}=0.5\left[\sqrt{\left(z_{v 2}-2\right)^{2}-\left(z_{v 2} \cos \phi_{t}\right)^{2}}-z_{v 2} \sin \phi_{t}\right]
\end{aligned}
$$

$k$ - action line contact length factor

The transverse contact ratio of the virtual spur gear for a straight bevel gear is [19]:

$$
\varpi_{t}=\frac{k_{1}+k_{2}}{\pi \cos \phi_{t}}
$$

$\varpi_{t}-$ virtual or effective transverse contact ratio

\subsection{A New Contact Stress Model}

Osakue and Anetor [19] presented a new contact stress model for straight bevel where a bevel gear load factor was defined. This factor provides a kinetic link between the physical bevel gear and virtual spur gear. The combination of the "Tredgold's approximation" and the "bevel load factor" help define an equivalent spur gear for a bevel gear. The proposed new contact stress model may be expressed as:

$$
\sigma_{H}=\left[\frac{2 K_{s} K_{H} K_{b}\left(\mu_{e}+1\right) \cos \varphi_{2} E_{c} T_{1}}{\lambda_{f} \varpi_{t} b d_{e 1} d_{e 2}}\right]^{\frac{1}{2}} \times 10^{3}
$$

$\lambda_{f}-$ effective face width factor

The expected effective face width factor based on ISO [7] and ANSI/AGMA [28] is in the range of $80 \%$ to $90 \%$. Because of some accommodations of contact conditions by the contact quality factor $K_{c}$ in Eq. (16?) and determination of pitch velocity at the backend of the bevel gear, $\lambda_{f}=$ 0.89 is recommended [20].

The similarities between Eqs. (23) and (28) are obvious. The differences are in the pitch diameters of the bevel gear and the bevel load factor. Eq. (21), can be formatted in the same way but is not done due the method AGMA uses in evaluating $Z_{I}$ factor.

\section{DESIGN APPLICATION CASES}

Table 1 shows the design data for six gears chosen for this study. Based on the information on Table 1, the gears were sized [19] and the preliminary basic dimensions for the six gearsets are presented in Table 2. Using the AGMA 2003 [5], ISO 10300 [6], and the new contact stress expressions discussed above, the contact stress predictions from the models were evaluated and Table 3 shows the results obtained. Evaluation methods for load service factor components are well documented in AGMA standards and those methods were adopted for the new contact stress model because they are simpler than ISO methods. Appendix A provides a summary for both AGMA and ISO methods for evaluating the components of the service load factor. We assumed that $K_{c}=1.1$ and $K_{r}=1.0$ in all the design cases considered. However, values for AGMA and ISO standards are equal to unity only at high values of rim backup ratios. At lower rim backup ratios, the ISO standard gives more conservative values than the AGMA standard. Table 4 gives the estimates of the service load factor and the load influence factors of internal overload and mounting overload. Table 5 shows the percentage variances between the new contact stress model and those of AGMA and ISO models, while Table 6 shows the percentage variances between the new model load influence factors and those of ISO model. 
Table 1: Design Input Data

\begin{tabular}{|c|c|c|c|c|}
\hline $\begin{array}{c}\text { Design } \\
\text { case }\end{array}$ & $\begin{array}{c}\text { Tooth } \\
\text { profile } \\
\text { quality }\end{array}$ & $\begin{array}{c}\text { Input } \\
\text { Power } \\
(\mathrm{kW})\end{array}$ & $\begin{array}{c}\text { Input } \\
\text { speed } \\
(\mathrm{rpm})\end{array}$ & $\begin{array}{c}\text { Gear } \\
\text { ratio }\end{array}$ \\
\hline 1 & 10 & 10 & 1750 & 1.00 \\
\hline 2 & 10 & 75 & 1140 & 2.00 \\
\hline 3 & 8 & 600 & 1140 & 3.00 \\
\hline 4 & 8 & 2500 & 1140 & 4.06 \\
\hline 5 & 7 & 4000 & 1140 & 5.18 \\
\hline 6 & 6 & 15000 & 1140 & 6.16 \\
\hline
\end{tabular}

Table 2: Gearsets Basic Dimensions

\begin{tabular}{|c|c|c|c|c|c|c|c|}
\hline \multirow{2}{*}{$\begin{array}{c}\text { Design } \\
\text { case }\end{array}$} & \multirow{2}{*}{$\begin{array}{c}\text { Backend } \\
\text { module } \\
(\mathrm{mm})\end{array}$} & \multicolumn{2}{|c|}{ Teeth number } & \multicolumn{2}{|c|}{$\begin{array}{c}\text { Backend Pitch } \\
\text { Diameter (mm) }\end{array}$} & \multicolumn{2}{|c|}{$\begin{array}{c}\text { Face width } \\
(\mathrm{mm})\end{array}$} \\
\cline { 3 - 8 } & Pinion & Gear & Pinion & Gear & Pinion & Gear \\
\hline 1 & 2.5 & 20 & 20 & 30 & 30 & 20 & 20 \\
\hline 2 & 5 & 20 & 40 & 100 & 200 & 35 & 35 \\
\hline 3 & 10 & 20 & 60 & 200 & 600 & 80 & 80 \\
\hline 4 & 15 & 17 & 69 & 255 & 1035 & 130 & 130 \\
\hline 5 & 20 & 17 & 88 & 340 & 1760 & 190 & 190 \\
\hline 6 & 25 & 17 & 105 & 425 & 2625 & 240 & 240 \\
\hline
\end{tabular}

Table 4: Estimated Load Influence Factors

Table 3: Contact Stresses and Pitch Velocities

\begin{tabular}{|c|c|c|c|c|}
\hline \multirow{2}{*}{$\begin{array}{c}\text { Design } \\
\text { case }\end{array}$} & \multicolumn{3}{|c|}{ Contact Stress (MPa ) } & \multirow{2}{*}{$\begin{array}{c}\text { Velocity } \\
(\mathrm{m} / \mathrm{s})\end{array}$} \\
\cline { 2 - 4 } & New Model & AGMA & ISO & \\
\hline 1 & 1271.96 & 1309.21 & 2128.50 & 4.582 \\
\hline 2 & 1127.15 & 1188.52 & 1360.15 & 5.970 \\
\hline 3 & 1159.82 & 1245.71 & 1443.52 & 11.940 \\
\hline 4 & 1294.44 & 1376.38 & 1365.27 & 15.223 \\
\hline 5 & 1175.14 & 1223.35 & 1447.46 & 20.297 \\
\hline 6 & 1524.89 & 1558.79 & 1424.68 & 25.372 \\
\hline
\end{tabular}

Table 5: Contact Stress Variances between

\begin{tabular}{|l|c|c|}
\hline $\begin{array}{l}\text { Design } \\
\text { Case }\end{array}$ & $\begin{array}{c}\text { AGMA Variance } \\
(\%)\end{array}$ & $\begin{array}{c}\text { ISO Variance } \\
(\%)\end{array}$ \\
\hline CASE 1 & 2.93 & 67.34 \\
\hline CASE 2 & 5.44 & 20.67 \\
\hline CASE 3 & 7.40 & 24.46 \\
\hline CASE 4 & 6.33 & 5.47 \\
\hline CASE 5 & 4.10 & 23.17 \\
\hline CASE 6 & 2.22 & -6.57 \\
\hline
\end{tabular}

\begin{tabular}{|c|c|c|c|c|c|c|}
\hline $\begin{array}{c}\text { Design } \\
\text { case }\end{array}$ & \multicolumn{2}{|c|}{$\begin{array}{c}\text { Service Load } \\
\text { Factor }\end{array}$} & \multicolumn{2}{|c|}{$\begin{array}{c}\text { Internal } \\
\text { Overload Factor }\end{array}$} & \multicolumn{2}{c|}{$\begin{array}{c}\text { Mounting } \\
\text { Overload } \\
\text { Factor }\end{array}$} \\
\hline & $\begin{array}{c}\text { New } \\
\text { Model }\end{array}$ & ISO & $\begin{array}{c}\text { New } \\
\text { Model }\end{array}$ & ISO & $\begin{array}{c}\text { New } \\
\text { Model }\end{array}$ & ISO \\
\hline 1 & 1.604 & 2.425 & 1.328 & 1.338 & 1.102 & 1.812 \\
\hline 2 & 1.784 & 2.267 & 1.366 & 1.251 & 1.187 & 1.812 \\
\hline 3 & 1.606 & 1.969 & 1.285 & 1.086 & 1.136 & 1.812 \\
\hline 4 & 1.943 & 1.964 & 1.318 & 1.083 & 1.341 & 1.812 \\
\hline 5 & 1.793 & 2.011 & 1.252 & 1.109 & 1.302 & 1.812 \\
\hline 6 & 2.443 & 2.007 & 1.277 & 1.107 & 1.739 & 1.812 \\
\hline
\end{tabular}

Table 6: Load Influence Factor Variances

\begin{tabular}{|l|c|c|}
\hline $\begin{array}{l}\text { Design } \\
\text { Case }\end{array}$ & $\begin{array}{c}\text { AGMA Variance } \\
(\%)\end{array}$ & $\begin{array}{c}\text { ISO Variance } \\
(\%)\end{array}$ \\
\hline CASE 1 & 2.93 & 67.34 \\
\hline CASE 2 & 5.44 & 20.67 \\
\hline CASE 3 & 7.40 & 24.46 \\
\hline CASE 4 & 6.33 & 5.47 \\
\hline CASE 5 & 4.10 & 23.17 \\
\hline CASE 6 & 2.22 & -6.57 \\
\hline
\end{tabular}

\section{DISCUSSIONS}

Fig. 4 shows the plot of the contact stresses in Table 3. From Fig. 4, it is obvious that the new and the AGMA 2003 [5] models give close predictions, with the new model values slightly lower. At high loads and velocities, the values from the two models appear to be converging. The ISO 10300 [6] model contact stress values seem to be very significantly higher at low loads 


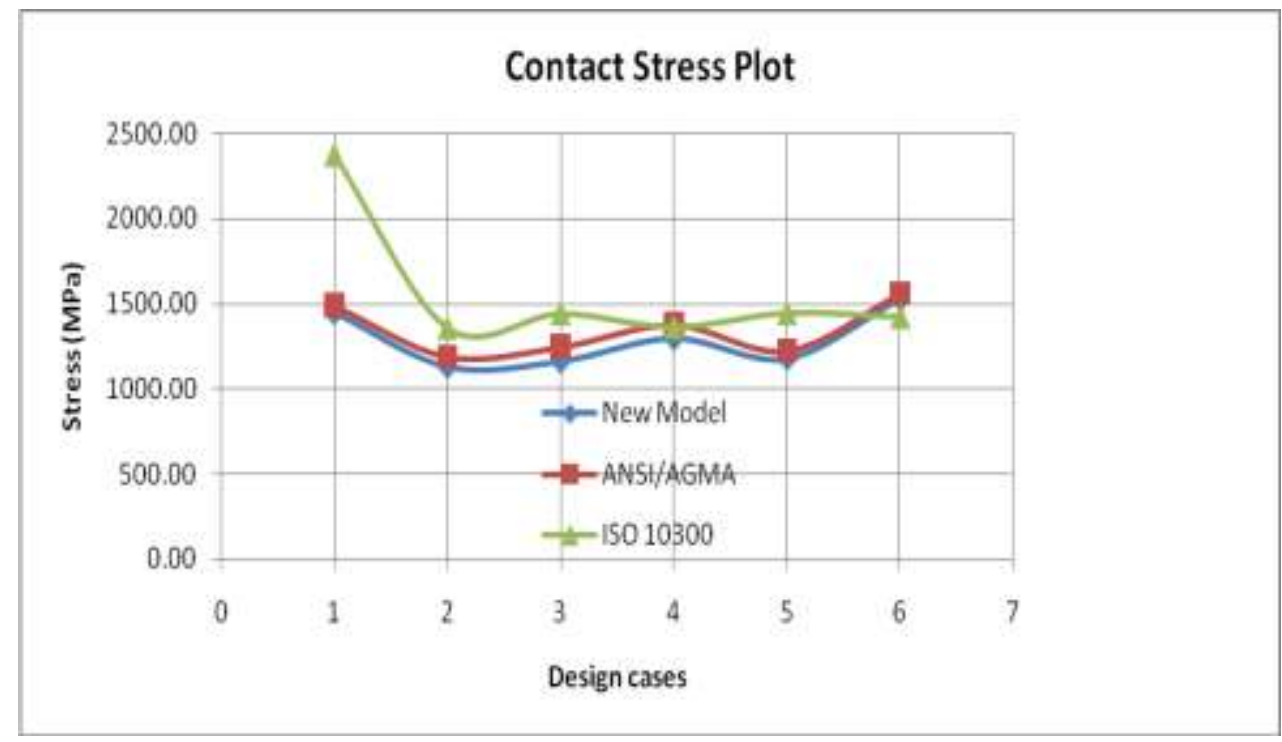

Fig 4: Contact stress estimates from models

and velocities than either the new model or AGMA values. However, at high loads and velocities the contact stress values from ISO 10300 appears to converge and even predicts lower contact stress values than either the new model or AGMA values. The shape of each curve is accentuated by the influence of crowning, which was applied only to design cases 1,3 , and 5. From Table 5, it is seen that the percentage differences between the new and AGMA 2003 models are in the range of $2.22 \%$ to $7.40 \%$. These differences are small but can mean significant improvement in the pitting life expectancy of the gears since life and contact stress is related by a power law of approximately 9 th degree [29]. For example, a 5\% decrease in contact stress could mean a pitting life increase of about $50 \%$. The percentage differences between the new and ISO models contact stresses are in the range of $-6.57 \%$ to $67.34 \%$. These are large differences, indicating that much shorter pitting life should be expected based on the ISO model. In Appendix A, it is shown that when $\lambda_{n}=\lambda_{r}=2.7$ for straight bevel gears of ISO standard proportions, the AGMA model predicts a value of 1.0 for $K_{r}$ while the ISO model predicts a value of 1.295 . Thus the service load factor for ISO model will be about $30 \%$ higher at this value of $\lambda_{n}$. When $2.7<\lambda_{n}<3.5$, ISO predicts values of $K_{r}$ that are above unity while AGMA model predicts a value of unity. Hence in that interval of values, the ISO gear will practically be larger in size.

At $\lambda_{n}=\lambda_{r}=3.5$ and above, the rim thickness influence is the same for both standards since $K_{r}=1$. Therefore, contact stress estimates for ISO standards in this study would be higher than obtained if $2.7 \leq \lambda_{n} \leq 3.5$ is assumed. According to Childs [1], ANSI/AGMA 2003 standard provides conservative contact and bending stresses for bevel gears. Hence, contact stress models slightly less conservative than AGMA standard should then be given serious consideration. Contact stress models more conservative than AGMA standard would seem to be in need of careful revision, in our opinion.

Fig. 5 shows the service load factor predictions from the new model and that of ISO 10300 methods. The AGMA values are the same as the new model values since the new model used the AGMA methods of evaluation. The service load values at low loads and speeds for the ISO model are higher than those of the new model. As the load and pitch velocity increase in values, the predictions from the two models appear to converge. However, they diverge again at very high loads and pitch velocity, where the estimates from the new model tend to be higher in values than those of the ISO model. 


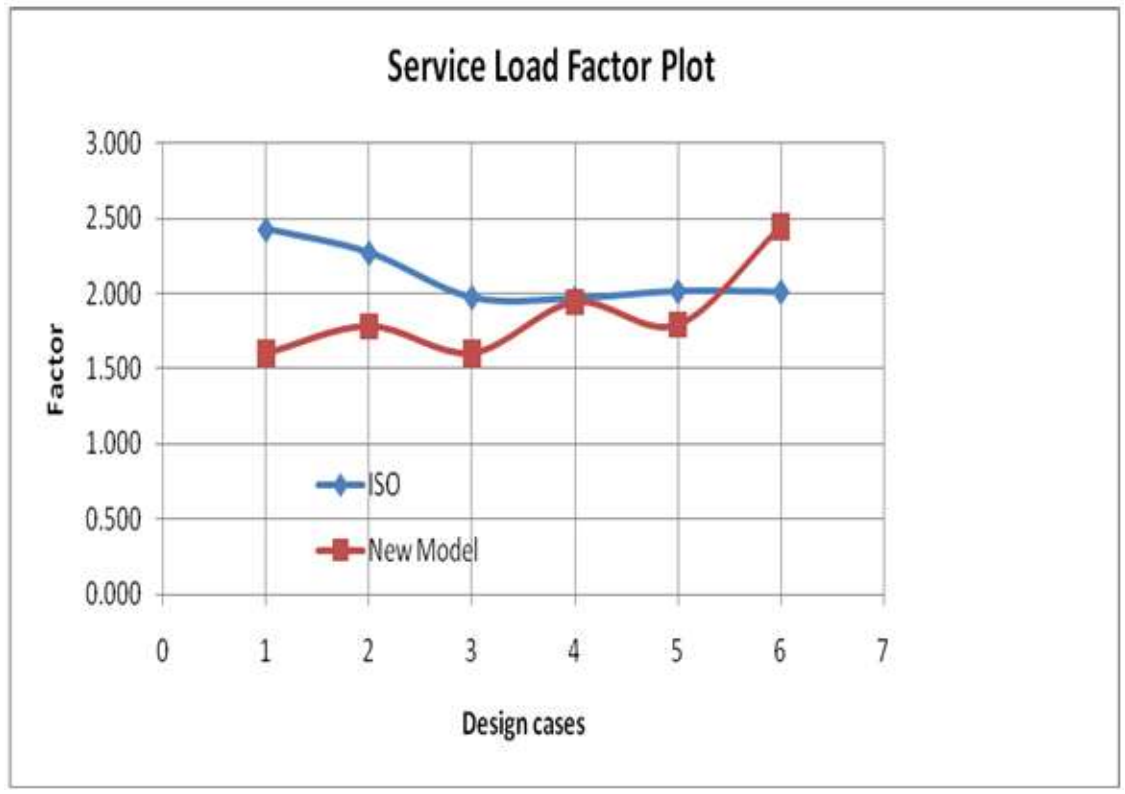

Fig 5: Service load factor estimates from models

Fig. 6 shows the plot of the internal overload factor for the new and ISO 10300 models. In the ISO 10300 bevel gear standard, the load coefficient values at low loads and speeds are higher than those at higher load and speeds. At higher loads and speeds, the velocity coefficients tend to be very low. As the pitch velocity increases, higher tooth quality is required which leads to lower values of the internal overload factor for the two model estimates. The new model estimates appear to be consistently higher at medium to high pitch velocities while the values from the ISO model appears to bottom out. Please see the Appendix A for a brief presentation of the formulas used in estimating the internal overload factor from the new and ISO methods.

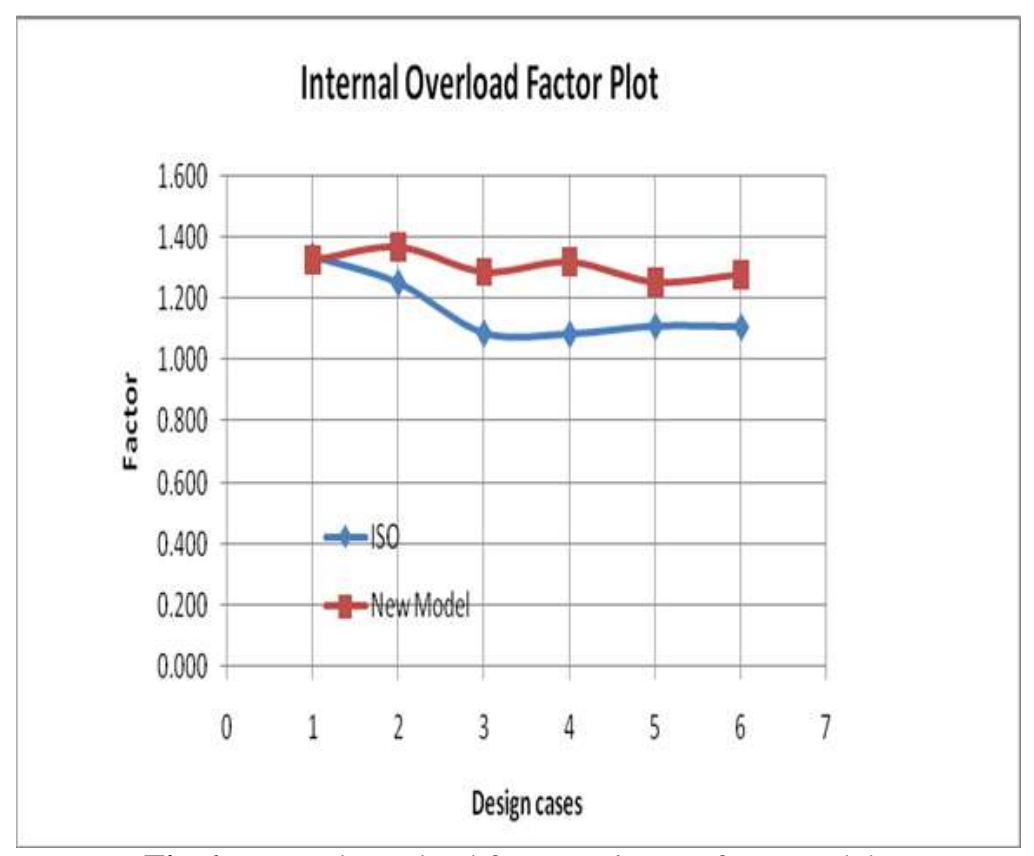

Fig 6: Internal overload factor estimates from models 


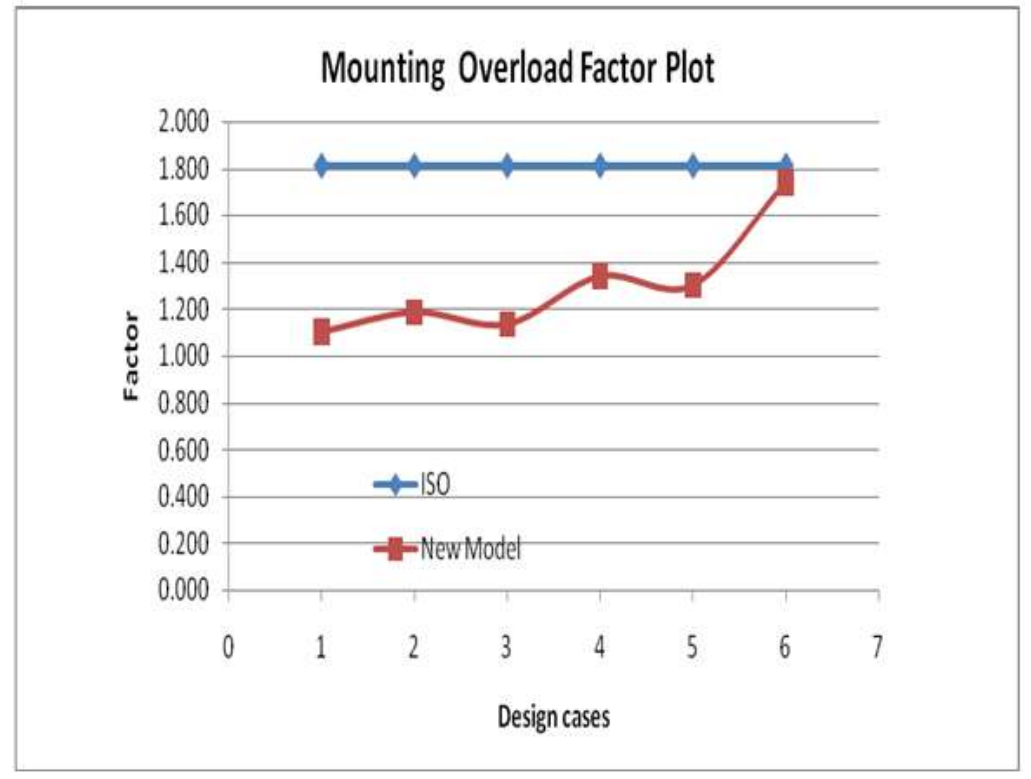

Fig 7: Mounting overload factor estimates from models

Fig. 7 shows the plot of the mounting overload factor from the model estimates. Thisplots show that the ISO model is insensitive to changing values of loads and pitch velocities. That is one value seems to apply to all design cases. The new model values are significantly lower in values at low loads and pitch velocities than those of ISO model. As the load increases, the required face width of the gearsets also increases. This leads to a corresponding increase in the value of the mounting overload factor which is proportional to the square of the facewidth in the AGMA evaluation method. Please refer to the Appendix A for the mounting factor models of the new and ISO methods.

As shown in Table 6, significant differences exist between the load influence factors predictions of ISO and the new models. The ISO model service load factor values differ from the new model values by $-17.87 \%$ to $54.80 \%$. The main contributors to these differences are the internal overload and mounting overload factors. As pointed out above, the rim flexibility factor is assumed to be unity for both ISO and AGMA models, making AGMA model very conservative. If AGMA recommendation of unity rim flexibility factor is assumed, the service load factor predictions from the ISO model will even be higher than those used in this study.

In Eq. (16?), five components of the service load factors have been selected as significant and they are largely based on experimental data. Experimental results are based on national and local design and manufacturing practices and the expertise of the investigators, so the data results may show some variations naturally. Hence from experimental data modeling perspective, similar component factor models may predict slightly different results due to the value differences in experimental data that the models simulate. Consequently, it is expected that the service load factor estimates from different gear standards may exhibit some differences as shown in Table 6. However, the large differences indicated in the table cannot just be attributed to experimental data variances and data modeling. Therefore, a careful examination of the evaluation methods and models for the internal overload and mounting overload factors in ISO standards seem appropriate, if not necessary.

There is widespread agreement that the Tredgold's geometric approximation specifies the backend cone radius of the physical bevel gear as the radius of the equivalent spur. Hence any bevel gear analysis model that adopts this approximation should of necessity use the backend cone radius of the bevel gear as the radius of the equivalent spur gear. However, the ISO model uses the mid facewidth plane to define the radius of the equivalent spur gear. Thus, it appears that such models are using a different approximation for the geometric equivalence for bevel gear. As can be verified easily by inspection of the contact stress Eqns. (23) for the ISO model and (28) for the new model respectively, the gear diameter parameters appear as denominators. Therefore, smaller values will result in higher contact stresses, while larger values lead to lower contact stresses. Because the backend diameters are larger than mid facewidth diameters, Eq. (28) of the new model will predict lower contact stress than Eq. (23) of the ISO standard that uses the mid facewidth diameters. Therefore, comparing ISO model results with the new or AGMA models is philosophically flawed because they use different approximations to define the equivalent spur gears. It is therefore not surprising to find significant differences when model results based on Tredgold's geometric approximation are compared with ISO models.

In AGMA bevel standards, many authors use the actual gear teeth number on the bevel gears $[1,2,3,6,30]$, to evaluate the $Z_{I}$ factor. However, some authors [31], use the virtual spur gear teeth number to evaluate the $Z_{I}$ factor. 
Conceptually, it is perhaps more appropriate to use the virtual teeth number when estimating $Z_{I}$ factor because the stress expression is based on that notion. Now when the virtual gear teeth numbers are used, there is the possibility of being out of range in the available AGMA charts, especially for the gears that normally have very high number of virtual teeth. Therefore, there appears to be some confusion in the estimation of $\mathrm{Z}_{\mathrm{I}}$ when AGMA bevel standard is used. It is refreshing that the new contact stress model completely eliminates these problems.

The new contact stress model incorporates a bevel load factor in its formulation and distinguishes between geometric and kinetic equivalence [19]. Perhaps lack of understanding the difference between geometric and kinetic equivalence may be responsible for mid-width plane and backend plane approaches in the AGMA and ISO models. It may also account for the use of mid-width and backend pitch velocity in evaluation of internal overload factor by different authors. The new model helps clarify these issues and avoids the inconsistencies.

\section{CONCLUSION}

In this study, the power range of 10 to $15,000 \mathrm{~kW}$, backend modules of 2.5 to $25 \mathrm{~mm}$ and backend pitch velocities of 4.58 to $25.37 \mathrm{~m} / \mathrm{s}$ were covered. Contact stress computations for six design cases were performed. The percentage differences in contact stress values between the new and AGMA 2003-B97 models are in the range of $2.22 \%$ to $7.40 \%$. Though the differences are small, they could significantly improve the pitting life expectancy of the gears since life and contact stress is related by a power law of approximately 9 th degree [29]. The percentage differences between the new and ISO 10300 models contact stresses are in the range of $-6.57 \%$ to $67.34 \%$. These are large differences, indicating that much shorter pitting life should be expected based on the ISO model. ANSI/AGMA 2003B97 standard provides a conservative means for estimating the contact and bending stresses in straight, zero, and spiral bevel gears and comparing the merits of different design proposals [1]. Due to the influence of stress on pitting life expectance, contact stress models yielding slightly less conservative values than AGMA standard should then be given serious consideration.

Current bevel gear design standards share three fundamental concepts of Hertz contact stress, spur gear equivalence based on Tredgold's geometric approximation, and load and strength influence modification factors. The Tredgold's approximation for the geometry of an equivalent spur gear of a bevel gear is near universal acceptance. It allows bevel gears to be designed with the geometric parameters defined at the backend of the bevel gear. However, differences exist in the application of Tredgold's approximation in that AGMA 2003-B97 applies it at the backend while ISO 10300 applies it at the mid-facewidth planes. Load influence factors are generally adopted so as to match theoretical gear capacity models such as pitting resistance with experimental data. Similarly, capability or strength influence factors are adopted so as to match gear material performance with experimental data. Differences in AGAM and ISO standards with respect to modification factors manifest in the number of factors considered important and the expressions developed for their estimation.

Significant differences in contact stress value estimates were observed in this study when AGMA 2003-B97 and ISO 10300 standards are used in estimating contact stress in straight bevel gear design. The ISO model contact stress values were found to be mostly higher than the AGMA values. A new contact stress model proposed yield contact stress values that are marginally smaller in values than those of AGMA. The differences in the contact stress value estimates may be attributed to the difference in the application of the Tredgold's geometric approximation in ISO standard and the AGMA standard or new model and the values of the load service factor. The equivalent spur gear pitch radius for ISO 10300 standard is smaller than the equivalent spur gear pitch radius for the new model or AGMA 2003-B97 standards; leading to higher contact stresses for the ISO 10300 standard. Secondly, the estimated values of the service load factor from the ISO standards were generally higher than those of the new model. So even if the Tredgold's approximation was applied identically in the different models or standards, the ISO results will still be higher in most cases.

While AGMA and ISO gear design philosophies and procedures are similar, the evaluation of specific parameters in the service load factor varies in the standards. The methods of parameter estimation seems to reflect differences in approach, assumptions, details in modeling and attempt to correlate theoretical models with experimental results. The evaluation of the components of the service load factor in the new model is the same as AGMA methods.

The maximum contact stress in a gear mesh should be determined with reasonable accuracy because the durability or pitting service life of gears depends on it. Due to the significant differences in contact stress values from AGMA and ISO standards, the differences in application of Tredgold's approximation and the models for the component parameters in the service load factor expression, it is concluded that comparing the results from these different standards seems inappropriate. The authors agree with KISSsoft [16] that there is need to harmonize ISO and AGMA bevel gear standards. Globalization of the economy and technology has made this a very important imperative.

\section{REFERENCES}

[1] Peter R. N., Childs, (2014), Bevel Gears, Mechanical Design Engineering Handbook, Butterworth Heinemann Elsevier, Boston, Chap. 10.

[2] Budynas, R. G. \& Nissbett, J. K., Shigley’s Mechanical Engineering Design, 9th ed., McGraw Hill Education. 
[3] Norton, R. L., (2000), Machine Design: An Integrated Approach, 2nd. ed., Prentice-Hall, Upper Saddle River, New Jersey.

[4] Kawalec, A, Wiktor, J, \& Ceglarek, D., (2006), Comparative Analysis of Tooth-Root Strength Using ISO and AGMA Standards in Spur and Helical Gears with FEM-bases Verification, Journal of Mechanical Design, Vol. 128, pp. $1141-1158$.

[5] ANSI/AGMA 2003-B97, https://www.agma.org/standards/ansi-agma-2003b97/

[6] . 10300-1, Calculation of load capacity of bevel gears, https://www.sis.se/api/document/preview/617914/

[7] DET NORSKE VERITAS, (2003), Calculation of Gear Rating for Marine Transmissions, Classification Notes, No.

41.2; https://rules.dnvgl.com/docs/pdf/DNV/cn/201205/CN41-2.pdf

[8] Collins, J. A., Busby, H., Staab, G. H., (2010), Mechanical Design of Machine Elements and Machines: A Failure Prevention Perspective, 2nd ed., John Wiley and Sons, New York.

[9] Abdoli, H., (2005), A Finite Element Approach to Spur, Straight Bevel and Hypoid Gear Design, Research Report in Mechanics, University of Oslo.

[10] Maitra, G. M., (2013), Fundamentals of Toothed Gearing: Handbook of Gear Design, 2nd ed., McGraw Hill, New Delhi.

[11] Joseph E. Shigley \& John J. Uicker,Jr, Theory of machines and mechanisms, McGrawHill (1995)

[12] Edward E. Osakue, (2016), Simplified Spur Gear Design, Proceedings of International Mechanical Engineering Congress and Exposition 2016 IMECE, Paper Number IMECE2016-65426, November 11-17, Phoenix Arizona, USA.

[13] Osakue, E. E. and Anetor, L. (2016), Spur Gear Design: Some New Perspectives, Int'l Journal of Research in Engineering and Technology, Vol. 5, Is. 7, pp. 275 - 286.

[14] McVittie, D., (1998), Calculating Spur and Helical Gear Capacity with ISO 6336, Gear Technology, pp. $11-14$.

[15] Walton, D., Shi, Y., \& Taylor, S. (1990), AGMA, ISO, and BS Gear Standards Part I-Pitting Resistance Rating, Gear Technology, p. $10-17$.

[16] KISSsoft, Bevel Rating Along AGMA 2003 in KISSsoft;

https://wenku.baidu.com/view/a3dbd8649b6648d7c1 c7460e.html

[17] Bergseth, E. (2009), Influence of Gear Surface Roughness, Lubricant Viscosity and Quality Level on ISO 6336 Calculation of Surface Durability, Technical Report, Department of Machine Design, Royal Institute of Technology, Stockholm, https://www.divaportal.org/smash/get/diva2:489751/FULLTEXT01.pd f (Accessed 2-20-16)
[18] Beckman, K. O, and Patel, V. P., Review of API Versus AGMA Gear Standards-Rating, Data Sheet Completion, and Gear Selection Guidelines, http//:turbolab.tmu.edu/proc/turboproc/t29pg191.pdf.

[19] Osakue, E. E. and Anetor, L. (2018), Design of Straight Bevel Gear for Pitting Resistance, FME Transactions 46, Vol.2, 194-204; doi:10.5937/fmet18021940.

[20] Osakue, E. E. and Anetor, L. (2018), Comparing Contact Stress Estimates of Some Straight Bevel Gears with ISO 10300 Standards, Proceedings of International Mechanical Engineering Congress and Exposition 2016 IMECE, Paper Number IMECE2018-86573, November 9-15, Pittsburgh, Pensylvania, USA.

[21] Mott, R. L. (2004), Machine Elements in Mechanical Design, 4th ed. SI, Pearson Prentice Hall, p. 392

[22] Zhao L, Frazer RC, Shaw B. Comparative study of stress analysis of gears with different helix angle using the ISO 6336 standard and TCA methods, http://eprint.ncl.ac.uk/file_store/production/231923/5 5884283-9446-4D06-A2EC-66A0CB6D7556.pdf

[23] ANSI/AGMA 2003-A86, Bevel Gear Rating Using The New Standard - AGMA 2003-A86 - Chegg www.chegg.com > study

[24] Gear Technical Reference - KHK Gears; http://khkgears.net/wpcontent/uploads/2015/10/gear_guide.pdf.

[25] Khurmi, R. S. \& Gupta, J. K., (2015), A Textbook of Machine Design, Eurasia Pub. House, New Delhi, p. 1084.

[26] ÖzbağcI, B., (2012), Effect Of Spiral Angle On Stress Distribution in The Spiral Bevel Gears, MSc. (MEng.) Thesis, Dokuz Eylül University Graduate School of Natural and Applied Sciences.

[27] Brown, M. D, (2009), Design and Analysis of a Spiral Bevel Gear, M. Thesis, Rensselaer Polytechnic Institute, Hartford, Connecticut, USA. https://pdfs.semanticscholar.org/7ed8/955de2331cb6 704dfb87880a31ebaded9a20.pdf

[28] ANSI/AGMA 2005--D03, Design Manual for Bevel Gears, $\quad$ p. $\quad 40 \quad-41$. http://allaboutmetallurgy.com/wp/wpcontent/uploads/2016/12/Design-Manual-for-BevelGears.pdf

[29] Townsend, D., P., (1986), Common Problems and Pitfalls in Gear Design, NASA Technical Memorandum 88858.

[30] Schmid, S. R., Hamrock, B. J. \& Jacobson,B. O., (2014), Fundamentals of Machine Elements, 3rd ed., CRC Press, New York.

[31] Gopinath, K \& Mayuram, M.M., Machine Design II, Lecture 14 - BEVEL GEARS PROBLEMS, http://nptel.ac.in/courses/112106137/pdf/2_14.pdf

[32] BS ISO 6336-1:1996, Calculation of load capacity of spur and helical gears, Part 1: Basic principles, introduction and general influence factors

[33] Charles D. Schultz, Introduction to Gear Design, 2nd Edition, Beyta Gear Service, Winfield, IL 
[34] ANSI/AGMA 2004, Fundamental Rating Factors and Calculation Methods for Involute Spur and Helical Gear Teeth, https://wp.kntu.ac.ir/asgari/AGMA\%202001-D04.pdf

[35] DET NORSKE VERITAS, (1993), Calculation of Gear Rating for Marine Transmissions, Classification Notes, No. 41.2

[36] https://rules.dnvgl.com/docs/pdf/DNV/cn/199307/99-V963.pdf

[37] Shigley, J. E and Mischke, C. R. (Chief Editors), (1996), Standard Handbook of Machine Design, McGraw-Hill, New York.

[38] Berezovsky, Y., Chernilevsky, D. \& Petrov, M, (1988), Machine Design, MIR Pub., Moscow.

[39] MITCal, Involute Gearing-Theory, www.mitcalc.com/doc/gear1/help/en/gear_theory.ht $\mathrm{m}$

\section{APPENDIX A: GEAR LOAD INFLUENCE FACTORS}

\section{Application Factor $\left(K_{a}\right.$ or $\left.K_{o}\right)$}

The factor $K_{a}$ adjusts the rated transmitted load value to compensate for external forces largely dependent on the characteristics of the driving and driven devices and the masses and stiffness of the system, including shafts and couplings used in service. The values of $K_{a}$ recommended by AGMA and ISO standards are basically the same.

\section{Internal Dynamic Load Factor $\left(K_{v}\right)$}

The internal dynamic factor relates the total tooth load to the rated transmitted tangential tooth load. It accounts for internal dynamic loads arising from acceleration and deceleration local masses of the geared unit. The internal dynamic loads are influenced by the quality of design and manufacturing. It is defined as:

$$
K_{v}=\frac{F_{t}+F_{d}}{F_{t}}=1+k_{v} \quad k_{v}=\frac{F_{d}}{F_{t}}
$$

$F_{d}-$ incremental internal dynamic load $(\mathrm{N})$

$k_{v}-$ incremental internal dynamic factor

AGMA provides expressions for $k_{v}$ - depending on the gear tooth quality in the range of 0 to 12 and the pitch velocity. According to AGMA [2] recommendations:

For $6 \leq q_{n} \leq 12$

$$
a_{1}=0.25\left(q_{n}-5\right)^{2 / 3}, a_{2}=50+56\left(1-a_{1}\right)
$$

$$
K_{v}=\left[1+\frac{\sqrt{200 V_{t}}}{a_{2}}\right]^{a_{1}}, V_{t}=\frac{\pi N d_{e} \times 10^{-3}}{60}
$$

$q_{n}$ - gear tooth profile quality number

$a_{1}$ - AGMA velocity exponent

$a_{2}$ - AGMA velocity coefficient

$V_{t}$ - Pitch point tangential velocity $(\mathrm{m} / \mathrm{s})$

Eq. (A3a) gives approximate values. For uni-directional loading, commercial quality gears should have $K_{v} \leq 1.5$ since Hamrock et al [30], suggest that a value of 1.43 is conservative. Smooth running gearsets should have $K_{v} \leq 1.25$ [33]. Precision drives generally have $K_{v}$ in the range of 1.02 to 1.11 [34], that is $K_{v}<1.15$. Therefore, as a guide for gear tooth profile quality selection, commercial quality gears may have $1.25<K_{v}<1.5$, premium quality gears may have $1.15 \leq K_{v} \leq 1.25$, and precision quality gears may have $K_{v}<1.15$. In these categories, lower values would mean higher processing cost. For high speed applications, especially those above $20 \mathrm{~m} / \mathrm{s}$, methods that account for gear material properties, mass and inertia of the gears, and actual tooth profile errors should be used to estimate $K_{v}$ [21]

\section{ISO Method C-Graphical}

ISO 6336-1 [32] provides several methods for estimating $K_{v}$ depending on desired accuracy. Method A has an experimental approach and a comprehensive analytical approach. The experimental approach uses direct measurements to determine overload while the comprehensive analytical approach considers load intensity, pitch velocity, elasticity of connected members, deflection of shafts and housing, damping, etc. and must be supported by experience with similar designs. Method B is a simplified analytical evaluation method assuming an elementary single mass and spring system and is not recommended for low speeds with $V_{o}$ less than $3 \mathrm{~m} / \mathrm{s}$ [31]. Method $\mathrm{C}$ is a simplified version of Method B and has both analytical and graphical versions. Method D is a further simplification of Method C and Method E adopts AGMA method.

According to Method-C graphical approach:

$$
K_{v}=1+\alpha_{o} K_{350 N}
$$

$K_{350 N}-$ velocity coefficient for $350 \mathrm{~N}$ resonance load

$\alpha_{o}-$ load correction factor 
Where:

$$
\alpha_{0}=f\left(q_{o}, q_{n}\right), q_{o}=\frac{K_{a} F_{t}}{b}
$$

$$
K_{350 N}=f\left(V_{o}, q_{n}\right), V_{o}=\frac{z_{1} V_{t}}{100} \sqrt{\frac{\mu^{2}}{\mu^{2}+1}}
$$
$q_{o}-$ Specific load (N/mm)
$V_{0}-$ Specific pitch point velocity $(\mathrm{m} / \mathrm{s})$

And

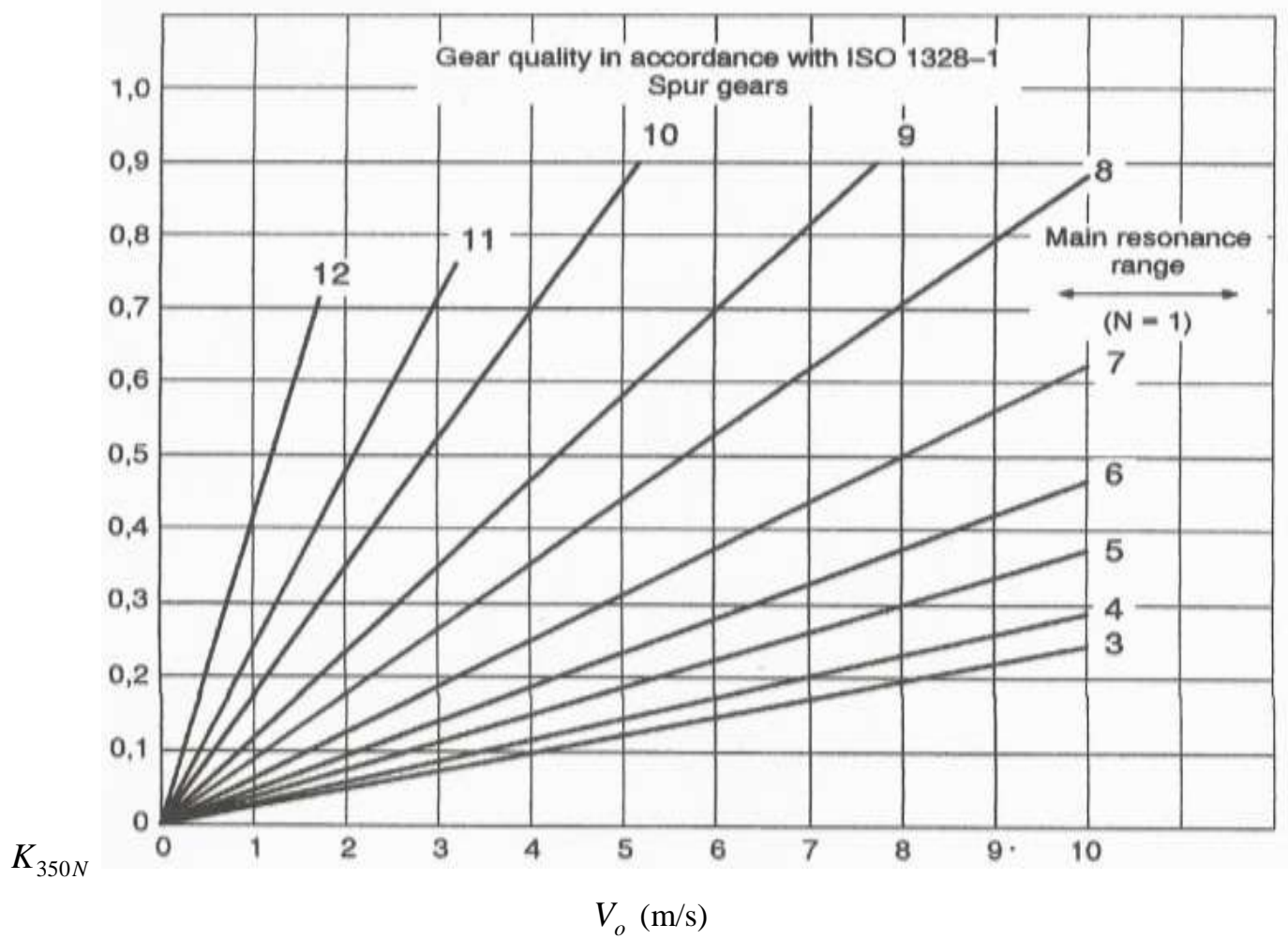

Fig 1: Spur gear dynamic load coefficient (Fig. 6 of BS ISO 6336-1) [32]

Table 1: Spur Gear Load Correction Factor $\left(\alpha_{o}\right)^{+}[32]$

\begin{tabular}{|c|c|c|c|c|c|c|c|c|c|}
\hline \multirow{2}{*}{$\begin{array}{l}\text { Gear Accuracy } \\
\operatorname{Grade}^{\mathrm{a}}\left(q_{n}\right)\end{array}$} & \multicolumn{7}{|c|}{ Specific Load (N/mm) $q_{o}$} \\
\cline { 2 - 9 } & $\leq 100$ & 200 & 350 & 500 & 800 & 1200 & 1500 & 2000 \\
\cline { 2 - 9 } & 1.61 & 1.18 & 1.00 & 0.93 & 0.86 & 0.83 & 0.81 & 0.80 \\
\hline 3 & 1.81 & 1.24 & 1.00 & 0.90 & 0.82 & 0.77 & 0.75 & 0.73 \\
\hline 4 & 2.15 & 1.34 & 1.00 & 0.86 & 0.74 & 0.67 & 0.65 & 0.62 \\
\hline 5 & 2.45 & 1.43 & 1.00 & 0.83 & 0.67 & 0.59 & 0.55 & 0.51 \\
\hline 6 & 2.73 & 1.52 & 1.00 & 0.79 & 0.61 & 0.51 & 0.47 & 0.43 \\
\hline 7 & 2.95 & 1.59 & 1.00 & 0.77 & 0.56 & 0.45 & 0.40 & 0.35 \\
\hline 8 & 3.09 & 1.63 & 1.00 & 0.75 & 0.53 & 0.41 & 0.36 & 0.31 \\
\hline 9 & 3.22 & 1.67 & 1.00 & 0.73 & 0.50 & 0.37 & 0.32 & 0.27 \\
\hline 10 & 3.30 & 1.69 & 1.00 & 0.72 & 0.48 & 0.35 & 0.30 & 0.24 \\
\hline 11 & 3.37 & 1.71 & 1.00 & 0.72 & 0.47 & 0.33 & 0.27 & 0.22 \\
\hline 12 & \multicolumn{7}{|c|}{} \\
\hline
\end{tabular}


The gear tooth quality number and specific load are used to determine the value of $K_{350 N}$ from the graph of Fig. A1 and the gear tooth quality and specific velocity are used to determine $\alpha_{o}$ from Table A1. Fig. A1 and Table A1 data apply only to spur gears.

From the above, both AGMA and ISO methods require the gear tooth quality number in estimating the internal overload factor. However, the ISO models also have the specific load which depends on the contact load and pitch velocity as variables. AGMA method is thus simpler and faster for estimating the internal overload factor.

\section{Mounting Overload Factor $\left(K_{m}\right)$}

The mesh or mounting overload factor, $K_{m}$ takes care of non-uniform load distribution along the tooth contact length due to gear teeth misalignments in a mesh. Misalignments generally result from the deflections of gear supporting members under load and clearances in bearings and housing; manufacturing accuracy, tooth width and spacing, and geometric characteristics of gear tooth. For bevel gears, values of $K_{m}$ are highly dependent on the mounting configuration of both pinion and gear. Preferred mounting configuration is for both gears to be straddle mounted, but this may not always be possible. So one-straddle and onecantilevered configuration is common in practice. Both gears may be cantilevered but this is a rare configuration in practice and is not recommended. AGMA standard 2003-

A86 [23] provides general methods for estimating $K_{m}$. Generally, it may be defined as:

$$
\begin{gathered}
K_{m}=\frac{q_{\max }}{q_{a}}=1+\frac{q_{i}}{q_{a}}, K_{m}=1+k_{m} \\
k_{m}=\frac{q_{i}}{q_{a}}
\end{gathered}
$$

$K_{m}$ - mounting or mesh overload factor

$q_{\text {max }}-$ maximum specific load $(\mathrm{N} / \mathrm{mm})$

$q_{i}$-incremental specific load ( $\left.\mathrm{N} / \mathrm{mm}\right)$

$q_{a}$ - average specific load (N/mm)

$k_{m}$-incremental specific load factor

The AGMA data for the gear mounting overload factor may be approximated as [2]:

$$
K_{m c}=K_{m o}+5.6 b^{2} \times 10^{-6}
$$

$K_{m c}$ - generic mounting or mesh overload factor

$$
K_{m o} \text { - basic mounting or mesh overload factor }
$$

For crowned gear teeth:

$$
K_{m}=K_{m c}(\mathrm{~A} 10 \mathrm{a})
$$

For uncrowned teeth higher values are expected [3] and from limited data [24], the values for uncrowned teeth appear to be in the range of 1.5 to 2.0 times the incremental specific load factor for crowned teeth. Therefore, for uncrowned teeth, it is suggested that:

$$
K_{m}=1+1.75\left(K_{m c}-1\right)
$$

Table A2 gives suggested values of $K_{m o}$

Table A2: Basic mounting Factor for Right Angle Crowned Bevel Gearset [8, p. 667].

\begin{tabular}{|l|c|}
\hline \multicolumn{1}{|c|}{ Gear Mounting Type } & $\begin{array}{c}\text { Basic Mesh Overload } \\
\text { Factor }\left(K_{m o}\right)\end{array}$ \\
\hline Both gears straddled & 1.00 \\
\hline One gear straddled & 1.10 \\
\hline Both gears cantilevered & 1.25 \\
\hline
\end{tabular}

ISO method for evaluating $K_{m}$ is a product of two components which are the face (axial) factor $\left(K_{m \beta}\right)$ and transverse (radial) factor $\left(K_{m \alpha}\right)$. This acknowledges possible contact stress variation in two directions. Thus:

$$
K_{m}=K_{m \beta} K_{m \alpha}
$$

$K_{m \alpha}$ - radial mounting transverse overload factor

$K_{m \beta}-$ axial mounting axial overload factor

From [7, p.14] $K_{m \alpha}=1.1$ for shaved teeth and 1.0 for ground teeth. Note that AGMA assumes $K_{m \alpha} \approx 1$; so only $K_{m \beta}$ is considered significant.

From [35]:

$$
K_{m \beta}=1.5 K_{m m}\left(\frac{0.85}{\lambda_{f}}\right)
$$

The range of $\lambda_{f}$ is 0.85 to 0.90 [7], but it is advisable to use actual value based on rated load test. Values of $K_{m m}$ are taken from Table A3, depending on bevel gear arrangement. 
Table A3: ISO Basic Mounting Factor for Bevel Gears [35]

\begin{tabular}{|l|c|}
\hline \multicolumn{1}{|c|}{ Mounting Configuration } & $\begin{array}{c}\text { Basic Mounting } \\
\text { Factor, } K_{m m}\end{array}$ \\
\hline Both gears straddled & 1.10 \\
\hline Small gear straddled & 1.15 \\
\hline Large gear straddled & 1.20 \\
\hline Both gears cantilevered & 1.30 \\
\hline
\end{tabular}

For Eq. (28), it is assumed that $\lambda_{s}=0.89$ and for the common case of a straddled pinion $K_{m m}=1.15$ so that:

$$
\begin{gathered}
K_{m \beta}=1.5 K_{m m}\left(\frac{0.85}{\lambda_{f}}\right) \\
=1.5 \times 1.15\left(\frac{0.85}{0.89}\right)=1.6475
\end{gathered}
$$

Assuming shaved teeth, $K_{m \alpha}=1.1$ :

$K_{m}=K_{m \alpha} K_{m \beta}=1.1 \times 1.6475=1.812$

From the above, values of $K_{m \beta}$ and $K_{m \alpha}$ for bevel gears in ISO 10300 are essentially fixed for all gear sizes. This is appears not to be in tune with practical expectations since housing and shaft rigidity vary depending on design, quality of manufacture, and assembly.

The mesh overload factor prediction by ISO 10300 [7] bevel gear standards varies from about 1.75 to 2.25 and the range of values is about 1.05 to 1.95 for crowned straight bevel gears based on AGMA graph [8]. The value range from Japanese standards is about 1.3 to 2.5 for crowned straight, zero, and spiral bevel gears and 1.3 to 3.8 for uncrowned straight bevel gears [24]. Clearly, the lower range values for ISO model appear to be on the high side when compared with the other standards mentioned above.

\section{Rim Flexibility Factor $\left(K_{r}\right)$}

The Lewis bending stress formula assumes a gear tooth attached to a perfectly rigid base support. This is true only if the gear rim is sufficiently rigid or thick enough. Large diameter gears of cast or fabricated construction having relatively thin rim are more flexible and may be subjected to low frequency vibration modes [28] that can cause gear failure. In both AGMA and ISO models, $K_{r}$ is conventionally applied to the root bending stress only. Because the vibrations associated with flexible gear rims increases the load during contact, then that load should influence the contact stresses also. Therefore, the authors believe the rim rigidity or flexibility factor should apply to both bending and contact stresses.

\section{AGMA}

Gear tooth base support rigidity is assessed by the rim backup ratio which is defined as the rim thickness divided by the whole depth of gear tooth. Experimental data suggest that when the rim backup ratio is greater than 1.2, the rim rigidity factor is unity, otherwise it is above unity. Based on AGMA [3] recommendation:

$$
\begin{gathered}
K_{r}=1.6 \ln \left[\frac{2.242}{\lambda_{r}}\right] \text { for } 0.5 \leq \lambda_{r}<1.2 \\
K_{r}=1.0 \text { for } \lambda_{r} \geq 1.2 \quad(\mathrm{~A} 15 \mathrm{~b}) \\
\lambda_{r}=\frac{t_{r}}{h_{t}} \quad(\mathrm{~A} 16)
\end{gathered}
$$

$\lambda_{r}-$ rim backup ratio

$t_{r}$ - rim thickness (mm)

$h_{t}-$ gear tooth whole depth (mm)

$m_{t}-$ transverse module $(\mathrm{mm})$

For standard ISO cylindrical and bevel gears, $h_{t}=2.25 m_{t}$. A rim back up ratio of $\lambda_{r}=1.2$ suggests a rim thickness, $t_{r}$ of 2.7 times the gear module for spur and straight bevel gears of ISO standard proportions. For a Gleason bevel gear system, the rim thickness, $t_{r}$ is about 2.63 times the gear module.

\section{ISO}

The ISO standard [7] has its own expression for $K_{r}$ and is based on similar concepts of gear tooth flexibility and resonance that can dramatically increase contact load. The expression is:

$$
\begin{gathered}
K_{r}=1.15 \operatorname{In}\left[\frac{8.324}{\lambda_{n}}\right] \text { for } 1.75 \leq \lambda_{n} \leq 3.5 \\
K_{r}=1.0 \text { for } \lambda_{n}>3.5 \quad(\mathrm{~A} 17 \mathrm{~b})
\end{gathered}
$$

Where:

$$
\lambda_{n}=\frac{t_{r}}{m_{n}}
$$

$\lambda_{n}-$ nominal rim backup ratio

$m_{n}$ - backend normal module (mm) 
For the ISO model, additional precaution is recommended for $\lambda_{n}<1.75$. Note that when $\lambda_{n}=\lambda_{r}=2.7$ for straight bevel gears of ISO standard proportions, the AGMA model predicts a value of 1.0 for $K_{r}$ while the ISO model predicts a value of 1.295. Thus the service load factor for ISO model will be about $30 \%$ higher at this value of $\lambda_{n}$. When $2.7<\lambda_{n}<3.5$, ISO predicts values of $K_{r}$ is above unity while AGMA model predicts a value of unity. Thus in that interval of values, the ISO gear will practically be larger in size. At $\lambda_{n}=\lambda_{r}=3.5$ and above, the rim thickness influence is the same for both standards since $K_{r}=1$. Though the AGMA and ISO methods for estimating $K_{r}$ are based on similar logic, values of $K_{r}$ could be very different sometimes depending on the backup ratio as demonstrated above.

\section{Contact Quality Factor $\left(K_{c}\right)$}

Tooth contact quality accounts for the effects of surface roughness, pitch line velocity, and lubrication effectiveness. Surface finish may be affected by manufacturing, heat treatment and surface treatment methods, residual stresses, plastic work hardening, etc. [2, 36]. In AGMA model, lubrication effective is not associated with this factor. The standard suggests it may be assumed to be unity for gears made with conventional methods but can be given a value above unity for unusually rough surface finish or for known presence of detrimental residual stresses [3]. Friction is generally associated with surface roughness and lubrication, and some suggested values for cylindrical and bevel gear meshes are 0.05 to 0.10 [37] and 0.04 to 0.08 [38]. However, in Hertz contact stress formulations for cylindrical and bevel gearing, mesh friction is neglected in most gearing standards because it is assumed to be negligible. But it is known that the presence of friction in Hertz contact increases the maximum contact pressure and introduces a tensile stress [3] in the stress field which is detrimental to fatigue resistance. Therefore, the contact quality factor may be justifiably given above unity value due to the presence of friction. The effect of surface roughness, pitch line velocity, and lubrication effectiveness is usually not more than $10 \%$ on gearing capability, according to McVillie [14]. For spur gears, a value of 1.10 was suggested in [12]. This value is assumed for straight bevel gears also.

\section{Appendix B: Simplifying ISO Bevel Model}

ISO 10300 contact stress model from [7, p. 17] for uncrowned straight bevel gears is simplified into:

$$
\begin{aligned}
& \sigma_{H}=1.05 Z_{E} Z_{\varepsilon} Z_{H} \sqrt{\frac{K_{s} F_{t} \cos \varphi_{1}}{d_{1} b}\left[\frac{\mu_{e}+1}{\mu_{e}}\right]} \\
& =1.05 Z_{E} Z_{\varepsilon} Z_{H} \sqrt{\frac{2 K_{s} T_{1} \cos \varphi_{1}}{d_{1}^{2} b}\left[\frac{\mu_{e}+1}{\mu_{e}}\right] \times 10^{3}}
\end{aligned}
$$

Where:

$$
Z_{H}=\sqrt{\frac{2 \cos \phi_{w t}}{\cos ^{2} \phi_{t} \sin \phi_{w t}}}
$$

$Z_{H}-$ zone factor for uncrowned gear teeth

$Z_{\varepsilon}-$ contact ratio factor

For gears with crowned teeth:

$$
\begin{aligned}
& \sigma_{H}=1.05 Z_{E} Z_{\varepsilon} Z_{M} \sqrt{\frac{K_{S} F_{t} \cos \varphi_{1}}{d_{1} b}\left[\frac{\mu_{e}+1}{\mu_{e}}\right]} \\
& =1.05 Z_{E} Z_{\varepsilon} Z_{M} \sqrt{\frac{2 K_{s} T_{1} \cos \varphi_{1}}{d_{1}^{2} b}\left[\frac{\mu_{e}+1}{\mu_{e}}\right] \times 10^{3}}
\end{aligned}
$$

$Z_{M}$ - zone factor for crowned gear teeth

That is, replace $Z_{H}$ with $Z_{M}$ in the equation (B1) above, where:

$Z_{M}=\sqrt{\frac{2 \tan \phi_{t} d_{t 1} d_{t 2}}{\left(\sqrt{d_{t o 1}^{2}-d_{t b 1}^{2}}-\varpi_{t} p_{b m}\right)\left(\sqrt{d_{t o 2}^{2}-d_{t b 2}^{2}}-\varpi_{t} p_{b m}\right)}}$

$p_{b m}-$ mid face width base circular pitch

Eqs. (B1) and (B3) may be combined and expressed as:

$\sigma_{H}=1.05 Z_{E} Z_{\varepsilon} Z_{H} \sqrt{\frac{2 K_{s} K_{x} T_{1} \cos \varphi_{1}}{d_{1}^{2} b}\left[\frac{\mu_{e}+1}{\mu_{e}}\right] \times 10^{3}}$

where for uncrowned tooth:

$$
K_{x}=\frac{Z_{H}^{2}}{Z_{H}^{2}}=1
$$


For crowned teeth

$$
\begin{aligned}
& K_{x}=\frac{Z_{M}^{2}}{Z_{H}^{2}} \\
& =\frac{d_{t 1} d_{t 2} \sin 2 \phi_{t} \tan \phi_{w t}}{2\left(\sqrt{d_{t o 1}^{2}-d_{t b 1}^{2}}-\varpi_{t} p_{b m}\right)\left(\sqrt{d_{t o 2}^{2}-d_{t b 2}^{2}}-\varpi_{t} p_{b m}\right)}
\end{aligned}
$$

Now

$$
\begin{aligned}
Z_{H} & =\sqrt{\frac{2 \cos \phi_{w t}}{\cos ^{2} \phi_{t} \sin \phi_{w t}}} \\
& =\sqrt{2 \pi \frac{2}{\pi \sin 2 \phi_{t}} \frac{\tan \phi_{t}}{\tan \phi_{w t}}} \\
& =\sqrt{2 \pi K_{f} K_{p}}
\end{aligned}
$$

Then from Eq. (22a) combined with Eq. (B7):

$$
Z_{E} Z_{H}=\sqrt{K_{f} K_{p} E_{c} \times 10^{3}}
$$

Also

$$
Z_{\varepsilon}=\sqrt{\frac{1}{\varpi_{t}}}
$$

Therefore, combining Eqs. (B5), (B8) and (B9):

$\sigma_{H}=1.05 \times 10^{3} \sqrt{\frac{2 K_{s} K_{f} K_{p} K_{x} T_{1} \cos \varphi_{1} E_{c}}{\varpi_{t} d_{1}^{2} b}\left[\frac{\mu_{e}+1}{\mu_{e}}\right]}$

Now substitute:

$$
\mu_{e}=\mu \frac{\cos \varphi_{1}}{\cos \varphi_{2}} \text { and } d_{2}=\mu d_{1}
$$

into the denominator and Eq. (15) into the numerator of Eq. (B10):

$$
\sigma_{H}=1.05 \times 10^{3} \sqrt{\frac{2 K_{s} K_{H} T_{1} \cos \varphi_{2}\left(\mu_{e}+1\right) E_{c}}{\varpi_{t} d_{1} d_{2} b}}
$$

Eq. (B12) is the combined equation for straight bevel gears. The mid-zone factor accounts for the effect of heightwise crowning and applies to spiral bevel gears [7]. The spiral bevel gear model is adopted for straight bevel gears here by setting the helix angle of the spiral bevel gear to zero.

It is noted that ISO standards generally require more details in the methods for evaluating load influence and strength influence factors than AGMA standards. 